\title{
Incidence, prevalence and risk factors for obesity among urban, adult Sri Lankans: a 7-year community cohort follow-up \\ Niriella MA ${ }^{1}$, De Silva ST ${ }^{1}$, Kasturiratne $A^{1}$, Ranasinghe RMAG ${ }^{1}$, De Silva AP ${ }^{1}$, \\ Pathmeswaran $\mathrm{A}^{1}$, Wickramasinghe $\mathrm{AR}^{1}$, Kato $\mathrm{N}^{2}$, de Silva $\mathrm{HJ}^{1}$ \\ ${ }^{1}$ Faculty of Medicine, University of Kelaniya, Sri Lanka \\ ${ }^{2}$ National Center for Global Health and Medicine, Tokyo, Japan.
}

\section{Background}

The risk of non-communicable diseases increases with increased body-mass index (BMI). 13\% of the world's population aged 18 years and over were obese, and 39\% were overweight in 2014 (WHO). The worldwide prevalence of obesity more than doubled between 1980 and 2014. Previous studies have estimated prevalence rates of $25.2 \%$, $9.2 \%$ and $26.2 \%$ for overweight, general obesity $(\mathrm{GO})$ and central obesity (CO) respectively, among Sri Lankan adults*. However, data on incidence and risk factors for GO and CO from the South Asian region is limited.

\section{Aims}

We investigated the incidence, prevalence and demographic and life style risk factors for GO and CO among urban, adult Sri Lankans in a 7-year prospective, community cohort follow-up study.

\section{Method}

We included urban, adult, Sri Lankans (selected by age-stratified random sampling) from Ragama Medical Officer of Health area in Gampaha District, Sri Lanka. The initial screening was done in 2007 (aged 35-64 years) and re-evaluation took place in 2014 (aged 4271 years).

On both occasions structured interview, anthropometry, liver ultrasound, biochemical and serological tests were performed. Total body fat (TBF) and visceral fat percentage (VFP) were assessed by impedance in 2014. GO was defined as $\mathrm{BMI}>25 \mathrm{~kg} / \mathrm{m}^{2}$. CO was defined as waist circumference (WC) $>90 \mathrm{~cm}$ for males and $>80 \mathrm{~cm}$ for females. Multinomial logistic regression was fitted to assess associations.

Table 1 - Prevalence and incidence of obesity

\begin{tabular}{|l|c|c|c|}
\hline \multicolumn{3}{|c|}{ Males } & \multicolumn{1}{|c|}{ Females } \\
\hline Prevalence & & & \\
\hline $\begin{array}{l}\text { Over-weight \% } \\
\text { (CI) }\end{array}$ & $22.0(0.19-0.24)$ & $19.6(0.17-0.21)$ & $20.7(0.19-0.22)$ \\
\hline GO \% (CI) & $29.5(0.27-0.32)$ & $47.0(0.44-0.49)$ & $39.1(0.37-0.40)$ \\
\hline CO \% (CI) & $34.3(0.32-0.37)$ & $69.2(0.66-0.71)$ & $53.4(0.51-0.55)$ \\
\hline Incidence & $2.1(0.1-0.04)$ & $2.5(0.01-0.04)$ & $2.4(0.02-0.04)$ \\
\hline $\begin{array}{l}\text { Over-weight \% } \\
\text { (CI) }\end{array}$ & $1.5(0.007-0.03)$ & $2.7(0.02-0.04)$ & $2.1(0.01-0.03)$ \\
\hline GO \% (CI) & $2.2(0.01-0.04)$ & $4.7(0.03-0.07)$ & $3.1(0.02-20.0)$ \\
\hline CO \% (CI) & & & \\
\hline
\end{tabular}

\section{Results}

In 2007 (n=2967), 614 (20.7\%) were overweight [51.9\% women], $1161(39.1 \%)$ had GO [65.9\% women] and 1584 (53.4\%) had CO [71\% women] (Table 1).

Female gender $(p<0.001)$, raised triglycerides $(p<0.001)$, low HDL $(p<0.001)$, diabetes $(p<0.001)$, hypertension $(p<0.001)$, non-alcoholic fatty liver disease (NAFLD) $(p<0.001)$, and low household income $(p<0.001)$ were significantly associated with prevalent GO and CO.

\section{Results}

Additionally, increased age $(p=0.05)$, low-educational level $(p<0.001)$ and unhealthy eating $(p<0.001)$ were associated with prevalent CO. Inadequate physical activity was not associated with either.

2137 (72\%) attended follow-up in 2014. Of those who were initially non-obese who attended follow-up, 189/1270 (14.9\%) [64\% women] had developed GO (annual incidence 2.13\%) and 206/947 (21.9\%) [56.3\% women] had developed CO (annual incidence 3.12\%) after 7 years (Table 1$)$.

Female gender, increase in age and waist circumference, high TBF and VFP and presence of NAFLD in 2007 were risk factors for new onset GO (Table 2).

Female gender, increase in BMI and waist circumference, high TBF and VFP, presence of diabetes and NAFLD in 2007 and low household income were risk factors for new onset $\mathrm{CO}$ (Table 3 ).

\section{Table 2 - Risk Factors for new onset GO}

\begin{tabular}{|lcccc|} 
& OR & SE & P value & $95 \% \mathrm{Cl}$ \\
\hline Female gender & 21.8 & 10.4 & $<0.001$ & $8.57-55.4$ \\
\hline Age & 0.9 & 0.01 & $<0.001$ & $0.86-0.93$ \\
\hline $\begin{array}{l}\text { Waist circumference } \\
\text { (above cut-off) }\end{array}$ & 6.9 & 1.9 & $<0.001$ & $4.06-11.74$ \\
\hline Increase in waist (>5\%) & 10.9 & 4.9 & $<0.001$ & $4.5-26.31$ \\
\hline High TBF & 5.6 & 2.9 & 0.001 & $2.03-15.38$ \\
\hline High VFP & 105.2 & 50.3 & $<0.001$ & $41.20-268.36$ \\
& & & & \\
\hline NAFLD & 2.9 & 0.65 & $<0.001$ & $1.90-4.52$ \\
\hline
\end{tabular}

Table 3 - Risk Factors for new onset CO

\begin{tabular}{|c|c|c|c|c|}
\hline & OR & SE & P Value & $95 \% \mathrm{Cl}$ \\
\hline Female gender & 9.2 & 3.25 & $<0.001$ & $4.57-18.37$ \\
\hline $\mathrm{BMI}>25 \mathrm{~kg} / \mathrm{m}^{2}$ & 4.4 & 1.17 & $<0.001$ & $2.60-7.43$ \\
\hline Increase in weight (5-10\%) & 9.8 & 4.74 & $<0.001$ & $3.76-25.30$ \\
\hline Increase in weight (>10\%) & 17.1 & 8.58 & $<0.001$ & $6.42-45.73$ \\
\hline High TBF & 5.9 & 2.13 & $<0.001$ & $2.89-11.00$ \\
\hline High VFP & 4.7 & 1.77 & $<0.001$ & $2.26-9.83$ \\
\hline Diabetes & 1.9 & 0.53 & 0.021 & $1.10-3.28$ \\
\hline NAFLD & 2.2 & 0.55 & $<0.001$ & $1.38-3.62$ \\
\hline Low income & 0.5 & 0.0009 & 0.002 & $0.33-0.77$ \\
\hline
\end{tabular}

\section{Conclusions}

This is the first community cohort follow up study in South Asia to report incidence and risk factors for adult obesity. The prevalence and incidence of $\mathrm{GO}$ and $\mathrm{CO}$ were high in this cohort. Both new onset GO and $\mathrm{CO}$ were independently associated with female gender, adverse anthropometry and NALFD. 